
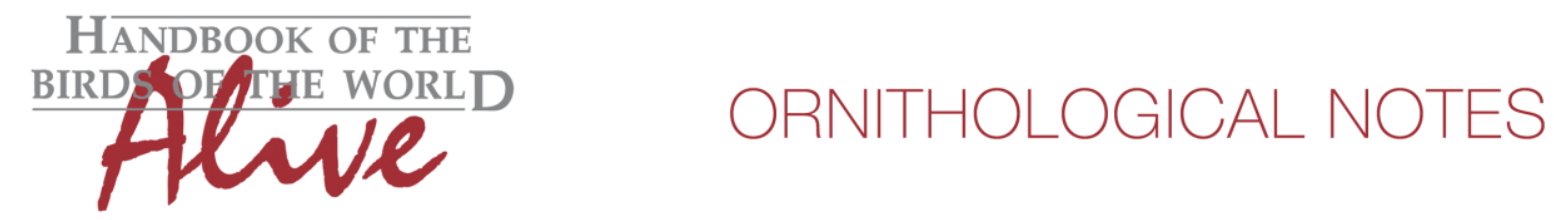

\title{
Notes on the vocalizations of Pearled Treerunner (Margarornis squamiger)
}

Peter Boesman

In the following we briefly analyze and compare voice of the different races of Pearled Treerunner (Margarornis squamiger). We also try to quantify the extent of any vocal differences using the criteria proposed by Tobias et al. (2010), as a support for taxonomic review.

We have made use of sound recordings available on-line from Xeno Canto (XC) and Macaulay Library (ML).

Pearled Treerunner has a variety of high-pitched vocalizations, varying from short single notes (also doubled and tripled) to longer rattles, either at a constant pitch or slightly going up and down, and with variable pace.

It is unclear which of these could be named 'territorial loudsong'. In literature there is also little clarity.

The fast high-pitched trill going up and down in pitch seems a good candidate to be named 'song', although it is heard much less than the stuttering rattles of high-pitched notes. The latter are however typically given in mixed-species flocks, when few birds really sing a territorial song.

The trill is often preceded by a variable number of higher-pitched notes or a stuttering rattle (Fig. 1).

We have measured a number of basic sound parameters for the fast trill:

North (perlatus) $(n=5)$

pace of trill

$0.031-0.050$

lowest top freq.

$6900-8700 \mathrm{~Hz}$

max. freq.

$8400-10900 \mathrm{~Hz}$ (when two birds counter-sing, they do at different pitch)

South (peruvianus/squamiger) $(n=2)$

pace of trill $\quad 0.026-0.028$

lowest top freq. $\quad 5700-6500 \mathrm{~Hz}$

max. freq. $\quad 7200-8200 \mathrm{~Hz}$

It would seem that this trill is slightly faster-paced and lower-pitched in southern birds, but given the low number of recordings and the high variability, this is quite speculative....

Also, the number of samples is not sufficient to check whether this change is gradual from north to south or really stable within every race.

We can thus conclude that there is a possible vocal difference (pace and pitch of up and down trill), but this needs to be confirmed by a larger number of samples. 

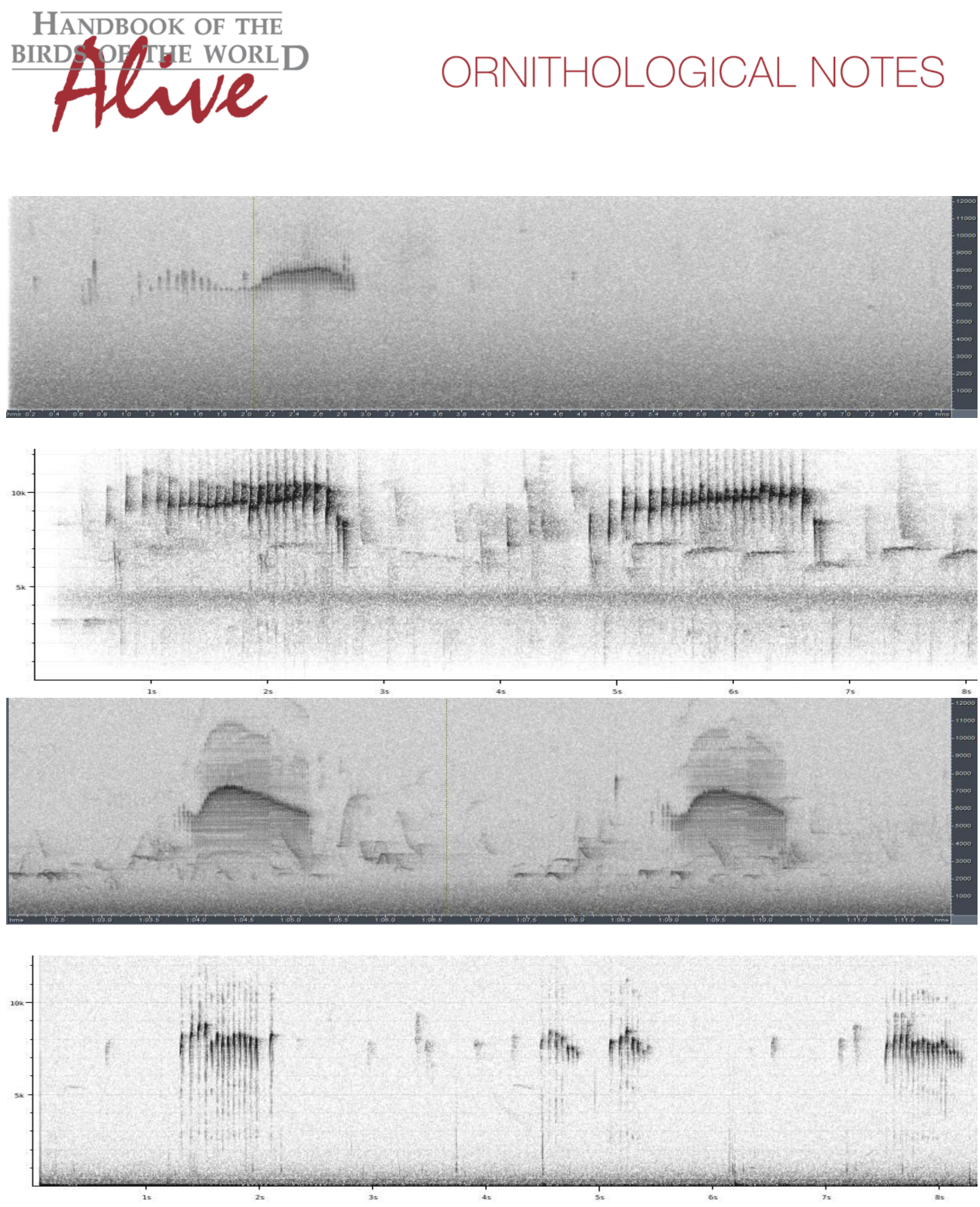

Figure 1: presumed song (fast trill) and high-pitched stuttering rattles of perlatus (top two) and peruvianus/nominate (bottom two)

This note was finalized on 20th June 2015 , using sound recordings available on-line at that moment. We would like to thank in particular the sound recordists who placed their recordings for this species on XC and ML: Peter Boesman, Thomas Donegan, Peter Hosner, Niels Krabbe, Dan Lane, Oscar Laverde, Bernabe Lopez-Lanus, Mitch Lysinger, Sjoerd Mayer, John V Moore, Andrew Spencer, Joseph Tobias and Krysztof Zyskowski. 


\section{References}

Tobias, J.A., Seddon, N., Spottiswoode, C.N., Pilgrim, J.D., Fishpool, L.D.C. \& Collar, N.J. (2010). Quantitative criteria for species delimitation. Ibis 152(4): 724-746.

\section{Recommended citation}

Boesman, P. (2016). Notes on the vocalizations of Pearled Treerunner (Margarornis squamiger). HBW Alive Ornithological Note 92. In: Handbook of the Birds of the World Alive. Lynx Edicions, Barcelona. (retrieved from http://www.hbw.com/node/931987 on 19 July 2016). 